\title{
The effects of prior training to imitate or nonimitate on subsequent susceptibility to social influence
}

\author{
ROBERT A. BARON, University of South \\ Carolina, Columbia, S.C. 29208
}

The effects of prior training to imitate or nonimitate on subsequent susceptibility to social influence were investigated. It was hypothesized that training Ss to imitate the responses of another individual would increase their susceptibility to social influence, while training Ss to nonimitate the responses of another individual would decrease such susceptibility. Results indicated that conformity behavior was inversely related to the level of task success attained by $S s$ during the imitation or nonimitation training phase of the experiment, but was not affected by the type of prior training (imitation or nonimitation) they received.

After many years of relative neglect, the phenomenon of imitative behavior has recently begun to receive considerable experimental attention (e.g., Flanders, 1968). Researchers concerned with imitative behavior have investigated such diverse topics as the conditions under which such behavior is acquired (e.g., O'Connell, 1965), the effects of models on helping behavior (e.g., Bryan \& Test, 1967), and the effects of models on fear reduction (e.g., Geer \& Turteltaub, 1967). Thus, a large amount of information on various aspects of imitative behavior has been acquired in recent years. However, to date, there has been no attempt to relate the findings of the current research on imitation to those reported in another, closely related area of research-that concerned with conformity behavior. It seems clear that these two areas of research are concerned with much the same phenomenon. Thus, it is surprising that no attempt has been made to relate them in a direct manner. The present experiment represents such an attempt. Specifically, it was designed to study the effects of prior training to imitate or nonimitate the responses of another individual on subsequent susceptibility to social influence. The procedures employed in the training of imitation and nonimitation were drawn from the experimental literature on imitation (e.g., Kanareff \& Lanzetta, 1960), while the procedures employed for investigating susceptibility to social influence were drawn from the literature on conformity behavior (e.g., Crutchfield, 1955). In this way, an attempt was made to forge a direct link between these two extensive bodies of research. It was hypothesized that training Ss to imitate the responses of another individual would increase their susceptibility to social influence, while training Ss to nonimitate the responses of another individual would decrease such susceptibility.

METHOD
Sixty male undergraduates enrolled in sections of elementary psychology at the University of South Carolina participated in the experiment. Subjects served in groups of four. When all four scheduled individuals were present, the $\mathrm{E}$ conducted them to the experimental room where they were seated at four individual tables. The tables had plywood screens on three sides to reduce visual contact among $\mathrm{Ss}$ to a minimum. Located on each table was a Lafayette 2000 Multi-Stimulus Display Unit. These units contained four rows of seven lights each, and seven red response buttons.

In the first part of the experiment (Part 1), Ss were told that their task was to predict which one of a pair of blue and green lights labeled "event lights" would come on on each of several different occasions. They were instructed to wait for a white signal light to come on and then go off before making their predictions. Ss were told that when the white signal light went off, they would be able to see the prediction made by another $\mathrm{S}$. This information was conveyed by a second pair of blue and green lights labeled "other's prediction." After they saw the other's prediction, Ss were to make their own prediction by pushing one of a pair of buttons labeled "prediction buttons." When they pushed one of these buttons, their own prediction was shown by a third pair of blue and green lights labeled "own prediction." All lights except this last pair were controlled by the E, and were illuminated according to prearranged schedules. These schedules were designed to vary the percentage of reinforcement for imitating the predictions of the other $S$. The five percentages of reinforcement for imitation were $0,20,50,80$, and $100 \%$.

After reading the instructions for Part 1, E retired to a second room which contained the master control unit for the individual $S$ units. E presented the stimuli and recorded Ss' responses (which were shown on the master control unit) in this room. There were 100 training trials in Part 1 of the experiment.

After completion of Part 1, the $E$ returned to the first experimental room and read the instructions for Part 2. E told Ss that this part was concerned with their ability to make certain types of auditory judgments. Their task was to judge whe ther the second tone in each of several pairs of tones was higher or lower in pitch than the first tone. The Ss were told to respond in a set sequence on each pair of tones. In order to determine their position within this sequence, Ss looked at a card which had been çoncealed behind the apparatus. This card informed all Ss that they were to go last, after all the other Ss had made their judgments. Thus, they were exposed to what were supposedly the judgments of the other three Ss before making their own judgments. In reality, these judgments (which were shown to Ss by means of three pairs of blue lights), were controlled by $E$ and followed a prearranged schedule. Ss were instructed to make their judgments by pushing one of two buttons labeled "judgment buttons" as soon as they saw that the Ss ahead of them in the sequence of responding had made their judgments.

There were 45 pairs of tones constructed from all possible combinations of tones of 800,900 , and $1000 \mathrm{cps}$. The judgments attributed to the other $\mathrm{Ss}$ were unanimously wrong on 27 of the 45 trials, and unanimously correct on the remaining trials. The tones were generated by a precision audiometer (Model E-310) and presented by means of a $3 \times 5$-in. speaker. Pilot data indicated that control Ss (i.e., individuals not exposed to the false group judgments) were able to make accurate judgments on approximately $98 \%$ of the tone pairs.

\section{RESULTS}

In order to determine if the different training conditions produced different levels of imitative behavior in Part 1 of the experiment, an analysis of variance was performed on the mean number of imitative responses (collapsed over trials) made by $\mathrm{Ss}$ in each of the five groups. The results of this analysis indicated that the effect of training condition (i.e., percentage of reinforcement for imitation) was significant ( $F=65.24$, df $=4 / 55, p<.001)$. As expected, the higher the percentage of reinforcement for imitation, the greater the number of imitative responses performed by Ss.

The dependent measure of major in terest was the mean number of conformity responses made by $S s$ in the five groups in Part 2. Conformity responses were defined as responses which agreed with incorrect group judgments. It was predicted that the number of conformity responses made by $\mathrm{Ss}$ would increase as percentage of reinforcement for imitation in Part 1 increased. 


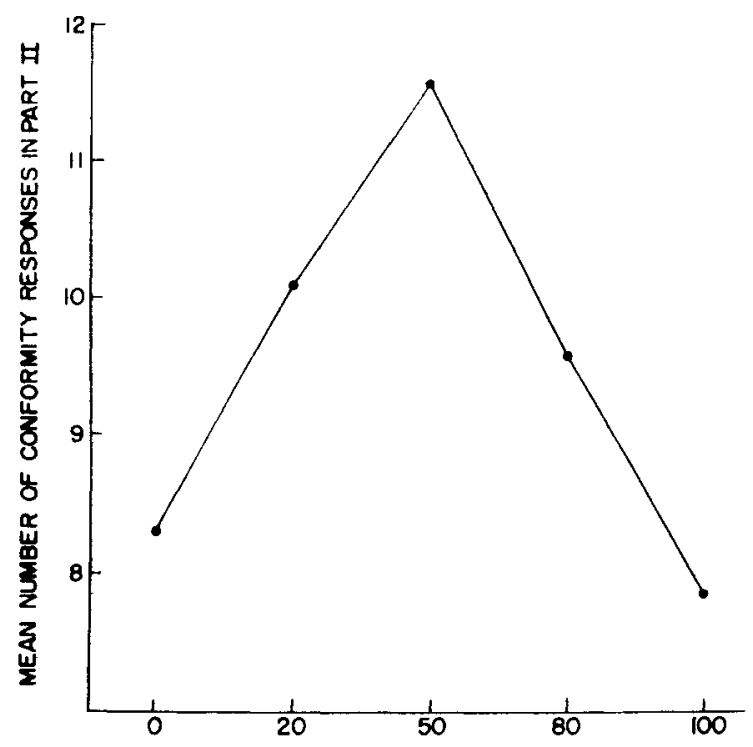

PERCENT REINFORCEMENT FOR IMITATION IN PART I
Fig. 1. Mean number of conformity responses in Part 2 as a function of per cent reinforcement for imitation in Part 1.
Figure 1 presents the mean number of conformity responses made by $\mathrm{Ss}$ in Part 2 as a function of percentage of reinforcement for imitation in Part 1. As can be seen, the hypothesis was not confirmed. Conformity was greatest for $\mathrm{Ss}$ trained at $50 \%$ reinforcement, and decreased as the percentage of reinforcement for imitation departed from this value in either direction. An analysis of variance performed on the data represented in Fig. 1 indicated that training condition in Part 1 had no effect on conformity behavior in Part $2(F<1)$. However, follow-up comparisons among the means for the five groups by Duncan multiple-range tests indicated that the $100 \%$ and $0 \%$ groups differed significantly from the $50 \%$ group, and that the $20 \%$ group differed significantly from the $100 \%$ group $(\mathrm{p}<.05)$.

The finding that conformity was maximum for the $50 \%$ group but decreased regularly as percentage of reinforcement for imitation departed from this value, suggested that conformity in Part 2 may have been influenced by Ss' level of task success in Part 1. In order to investigate this possibility, the mean number of correct (as opposed to imitative) responses made by Ss in each group was calculated. The means for the $0,20,50,80$, and $100 \%$ groups were $85.4,73.8,54.3,57.9$, and 84.7 , respectively. These means were then correlated with the mean number of conformity responses made by $\mathrm{Ss}$ in Part 2. The correlation obtained was quite substantial $(r=-.72$, $\mathrm{df}=58, \mathrm{p}<.01)$, and suggested that the greater the task success attained by $S s$ in Part 1, the less conformity they showed in Part 2.

\section{DISCUSSION}

The hypothesis that training Ss to imitate the responses of another individual would increase their susceptibility to social influence while training Ss to nonimitate the responses of another individual would decrease such susceptibility was not confirmed. Results indicated that maximum conformity occurred among Ss trained at $50 \%$ reinforcement for imitation, and decreased as departures from this percentage of reinforcement increased in either direction. The finding of a high negative correlation between the mean number of correct responses made by Ss in Part 1 and the mean number of conformity responses made by $S s$ in Part 2, suggests that this pattern of findings may have been produced by the different levels of task success attained by Ss in the five groups in Part 1 . The results of previous experiments (e.g., Kelman, 1950; Mausner, 1954) have indicated that prior success on a given task leads to reduced susceptibility to social influence, while prior failure leads to increased susceptibility to social influence. The results of the present experiment are consistent with these previous findings.

The finding that the relatively strong tendencies to imitate or nonimitate built up in the $100 \%$ and $0 \%$ groups during Part 1 failed to generalize to Part 2 is somewhat surprising. One possible explanation for this result may be that the gradient for imitative and nonimitative response tendencies is very steep along the dimension of task similarity. That this may indeed be the case is suggested by the results of a previous experiment (Croner \& Willis, 1961). This experiment found that experiences in one situation affected susceptibility to social influence in a second situation only when $E$ made an explicit and elaborate attempt to relate the two situations for the Ss. Thus, the results of this previous study, as well as those of the present experiment, suggest that generalization of imitative and nonimitative response tendencies from one situation to another will occur only when the situations in question are highly similar. Further investigations are planned to determine the dimensions of task similarity which may influence such generalization.

\section{REFERENCES}

BRYAN, J. H., \& TEST, M. A. Models and helping: Naturalistic studies in aiding behavior. Joumal of Personality \& Social Psychology, 1967, 6, 400-407.

CRONER, M. D., \& WILliS, R. H. Perceived differences in task competence and assymetry of dyadic influence. Journal of Abnormal \& Social Psychology, 1961, 62, 705-708.

CRUTCHFIELD, R.S. Conformity and character. American Psychologist, 1955, 10, 191-198.

FLANDERS, J. P. A review of research on imitative behavior. Psychological Bulletin, $1968,69,316-337$

GEER, J. H., \& TURTELTAUB, A. Fear reduction following observation of a model. Journal of Personality \& Social Psychology, 1967, 6, 327-331.

KANAREFT, V. T., \& LANZETTA, J. T. Effects of task definition and probability of reinforcement upon the acquisition and extinction of imitative responses. Journal of Experimental Psychology, 1960, 60, 340-348.

KELMAN, H. C. Effects of success and failure on "suggestibility" in the autokinetic situation. Journal of Abnormal \& Social Psychology, $1950,45,267-285$.

MAUSNER, B. The effects of prior reinforcement on the in teraction of observer pairs. Joumal of Abnormal \& Social Psychology, 1954, 49, 65-68.

O'CONNELL, E. J., JR. The effect of cooperative and competitive set on the learning of imitation and nonimitation. Journal of Experimental Social Psy chology, 1965, 1, 172-183.

\section{NOTE}

1. The author wishes to express his appreciation to Constance A. Miller for her assistance in the collection of the data, and to Dr. Richard A. Kasschau for his assistanœ in the preparation of this manuscript. 